BROCAR, 22 (1998) 103-120

\title{
AMÉRICA Y EL PROYECTO DE COMPAÑÍAS PRIVILEGIADAS DE JOSÉ DE CARVAJAL (1745-1754)*
}

\author{
José Miguel Delgado Barrado**
}

\begin{abstract}
"[Las compañías privilegiadas son]... valuartes y muros inexpugnables en que funda, y con razón, su mejor defensa la Monarquía. Sin ellas quedará el comercio tan lánguido como antes estaba, y con ellas puede florecer tanto que, acumulando riquezas, se llegue no sólo a la independencia, sino es a poner terror a los enemigos. Si ellas se aumentaran abundará el dinero, que es la verdadera sangre del Estado, multiplicará el real erario sus ingresos y conseguirán todos los vasallos la felicidad que vuestra Majestad les quiere derramar..."
\end{abstract}

En el siglo XVIII América jugó un papel importante en las políticas nacionales e internacionales de los principales estados europeos y sus riquezas comerciales motivaron conflictos bélicos y diplomáticos. España, poseedora del teórico monopolio comercial en la América Hispánica, intentó frenar, en la medida de sus posibilidades, el avance de otros estados en sus tradicionales dominios americanos adquiridos durante la conquista ${ }^{2}$.

En este proceso de expansión comercial las compañías privilegiadas de comercio jugaron un papel destacado. Estas compañías fueron elementos polí-

* Este artículo está incluido dentro del proyecto de investigación "América en la Economía Española (1648-1808), DGYCIT, no 1995-0250-C02-02, dirigido por el Dr. Carlos Martínez Shaw.

** UNED, Madrid

1. Véase esta cita en la obra de GIL DE JAZ, I. Informe de... sobre la representación hecha al Rey por José de Carvajal y Lancáster [1752]. Semanario Erudito de Valladares. Tomo XXII. Madrid, 1789.

2. José de Carvajal señaló en el Testamento Político o idea de un Gobierno Católico [1745], que las principales posesiones ilícitas inglesas eran Nueva Georgia, islas de Roatan, Utila, Granada y zona de la costa de Honduras; las holandesas en Surinám y zonas del río Orinoco; las de Dinamarca en la isla de Santa Cruz; y las francesas en la isla Española y Misisipí. 
ticos, económicos, defensivos y culturales, en manos del Estado y de una minoría comerciante. En España intentaron establecerse a imitación de las grandes compañías holandesas, inglesas y francesas, aunque con diversos resultados.

Durante el siglo XVIII podemos hablar de una corriente política favorecedora de las compañías privilegiadas en España, Francia, Dinamarca, Prusia, Portugal y algunos estados italianos, como el reino de las Dos Sicilias. Este fenómeno tardío, frente a la práctica holandesa e inglesa, responde a una de las fases de expansión comercial de la Edad Moderna.

La política comercial española fracasó con los proyectos y fundaciones de la Compañía Náutica (1701), la de Honduras (1714), Galicia (1734), y otras; y obtuvo éxitos con la Real Compañía Guipuzcoana de Caracas (1728), La Habana (1740), Barcelona (1755) y Filipinas (1785). Los resultados de la práctica reformista marcaron los constantes debates entre partidarios y detractores de las compañías, demostrando que no todos los estados eran proclives a compañías privilegiadas, ni sus éxitos estaban garantizados.

Estos debates fueron políticos, en la medida que los responsables del gobierno de la Monarquía Hispánica polemizaron sobre las compañías privilegiadas, y teóricos, en tanto que los escritores político-económicos de la época discutieron los beneficios y perjuicios de las compañías. En la mayoría de los casos los debates políticos y teóricos estuvieron representados por unos mismos protagonistas, los estadistas, hombres de gobierno y responsables políticos de los reinados de Felipe $V$ y Fernando VI: Uztáriz, Zabala, Patiño, Campillo, Carvajal, Argumosa, Sotomayor, Ensenada y otros. Así podemos considerar que las compañías privilegiadas de comercio fueron un hecho estructural en la política comercial española de la primera mitad del siglo XVIII.

En este artículo prestaremos más atención a las fases del discurso teórico de la primera mitad del siglo XVIII. La primera fase comprende desde las ideas de Gerónimo de Uztáriz (1724) y Zabala (1732) hasta la guerra hispano-inglesa de 1739. La segunda fase, entre 1739-1754, contiene un mayor dinamismo en los proyectos de compañías privilegiadas representado en los escritos de Amor de Soria (1740), Dantini (1741-1748) y Argumosa (1743), promovido por la Junta Extraordinaria de 1749-1750, y ejemplificado en los planes de reforma de José de Carvajal y Lancáster, principal objetivo de estas líneas.

No podemos asegurar que la guerra contra Inglaterra de 1739, donde España intentó preservar sus privilegios monopolísticos en América, fuese el origen de la formulación de estos proyectos. Sin embargo este impulsó la búsqueda de una doble solución a la presencia extranjera en América Hispánica: el empleo masivo de registros sueltos y las compañías privilegiadas de comercio. Precisamente uno de los objetivos de estas compañías era la extinción del contrabando, tanto nacional como extranjero, por medio de la presencia física y activa de barcos y hombres en determinadas áreas de América. De esta manera los proyectos de compañías, ya fuesen universales, regionales o provinciales, 
nacieron como respuesta y solución a los males del comercio colonial, fomentando las exportaciones nacionales y facilitando una mayor agilidad en los ritmos de intercambio.

Estos hechos aparecen reflejados en las ideas político-económicas, proyectos y política comercial de José de Carvajal y Lancáster (1698-1754), ministro de Fernando $\mathrm{VI}$, nexo de unión entre la defensa de las compañías y las nuevas estrategias de política comercial proporcionadas por el reformi smo carolino. Así este artículo pretende estudiar algunos proyectos marítimos de José de Carvajal relacionados con el comercio americano, en concreto los proyectos de compañías privilegiadas de comercio, su génesis y las transmisión de sus ideas.

\section{José de Carvajal y Lancaster, político y escritor (1698-1754)}

La vida política de José de Carvajal y Lancáster (1698-1754) desde su nombramiento como alcalde de la Sala de hijosdalgos (1729), pasando por los cargos de ministro de Estado, presidente de la Junta de Comercio y Moneda y decano del Consejo de Estado (1746-1754), y hasta su repentina muerte, estuvo rodeada de grandes acontecimientos políticos, económicos y culturales.

La historiografía española ha prestado poca atención a Carvajal, al menos como un estadista interesado por las cuestiones económicas, tal vez eclipsado por la figura del marqués de la Ensenada. Las líneas generales de su formación académica, primeros pasos políticos y el cenit de su carrera, fueron trazadas por Ozanam ${ }^{3}$. Algunos historiadores han destacado más sus labores diplomáticas que económicas ${ }^{4}$, señalando como principales elementos de su política la paz, el equilibrio y la salvaguardia de la Monarquía ${ }^{5}$.

3. Véase OZANAM, D. Diplomacia de Fernando VI. Correspondencia entre Carvajal y Huéscar (1746-1749), C.S.I.C. Madrid, 1975, 7 y sigs. Precisamente el tándem político Carvajal-Ensenada ha sido recientemente estudiado por GÓMEZ URDÁÑEZ, J.L. El proyecto reformista de Ensenada. Milenio, Lleida, 1996, en especial 81-126, que además cuenta con una excelente bibliografía. Otra referencia complementaria a las anteriores es el trabajo de ALCARAZ GÓMEZ, J.F. Jesuitas y reformismo. El padre Francisco de Rávago (1747-1755). Facultad de Teología San Vicente Ferrer. Series Valentina. Valencia, 1995, y las páginas que dedica a la trilogía formada por Rávago-Carvajal-Ensenada.

4. En este plano diplomático Carvajal recorrerá todos los escenarios políticos: la conferencia de Breda (4 de octubre de 1746); la paz de Aquisgrán (abril-octubre de 1748); el tratado hispano-portugués de Límites (13 de enero de 1750); el tratado anglo-español (5 de octubre de 1750); el tratado de Aranjuez (14 de junio de 1752); etc.

5. Este ideario político fue reflejado en sus escritos. Por ejemplo, en el Testamento Político, op.cit., dedicó numerosas páginas a la necesidad de cambiar la política exterior española, alejándose de la tradicional alianza con Francia y sustituyéndola por un acercamiento a Portugal, Austria e Inglaterra, enemiga tradicional de la Monarquía Hispánica. Véase un análisis muy general de esta obra en ESCUDERO, J.A. Los orígenes del Consejo de Ministros en España. Editora Nacional. Madrid, 1979, 203-208. 
El objetivo de estas líneas no es mostrar a Carvajal como ministro de Estado o estadista, sino su faceta de escritor político-económico e ideólogo, directa o indirectamente relacionados con buena parte de las medidas comerciales e industriales de la época. Estas responsabilidades político-comerciales fueron un hecho, a pesar de que desconocemos los límites de las competencias ministeriales de Carvajal y Ensenada. Recordemos que José de Carvajal fue presidente de la Junta de Comercio y Moneda entre 1746-1754 ${ }^{6}$. Como apunta Lynch:

"... Carvajal era presidente del Consejo de Indias, organismo en reg resión; Ensenada era secretario de las Indias, cargo en ascenso. El secretario detentaba el poder real y remitía escaso material al Consejo, aparte de los litigios. Así pues, las cuestiones económicas y administrativas estaban en manos de Ensenada, que trataba con América, por la vía reservada, es decir a través de la forma real, recortando, pues, las atribuciones del Consejo y de Carvajal en la política americana..."'.

José de Carvajal combinó responsabilidades políticas y la redacción de un ideario teórico centrado en tres escritos: el "Testamento Político" (1745); la "Representación" (1752) y "Mis Pensamientos" (1753), además de la correspondencia epistolar8.

Estas obras prestan especial atención al fomento comercial e industrial de la Monarquía Hispánica, en especial del comercio americano, analizando el asiento de negros, el navío de permiso, las reales compañías de fábrica y las compañías privilegiadas de comercio. Todos estos intereses fabriles y comerciales se relacionan directamente con la importancia de América y su papel protagonista en el fomento de la economía española del siglo XVIII'.

Sobre el asiento de negros escribe a Huéscar:

6. Véase a este respecto FRANCISCO OLMOS, J.M. Los Miembros del Consejo de Hacienda (1722-1838) y Organismo Económicos-Monetarios. Castellum. Madrid, 1997.

7. Véase LYNCH, J. El siglo XVIII. Editorial Crítica, Barcelona, 1991, 156. Esto mismo fue apuntado por ESCUDERO, J.A. Los orígenes del Consejo..., op.cit., 163-202.

8. Los títulos completos de las obras de Carvajal son: Testamento Político o idea de un Gobierno Católico; Mis Pensamientos o Pensamientos del Sr. Doo José de Carvajal sobre el estado político; y Representación hecha al Rey por ... sobre un Decreto que abolía las exenciones exclusivas que gozaban algunas compañías. El Testamento Político..., aunque fechado en 1745, fue publicado en el Almacén de Frutos Literarios en 1818, aunque cuenta con numerosas copias manuscritas en la Biblioteca del Palacio de Madrid y en la Biblioteca Nacional; la Representación ... de 1752 aparece publicado en el Semanario Erudito de Valladares de 1789; y Mis Pensamientos..., están incluidos en el apéndice documental de la obra de MOZAS MESA, $M$. Don José de Carvajal y Lancáster. Jaén, 1924.

9. En el contenido del Testamento Político, op.cit, aparecen los siguientes temas: Religión, Política (internacional), Guerra, Marina, Hacienda, Rentas Generales, Comercio (en general), Gracia y Justicia, Indias, Estado de Indias, Guerra de Indias, Marina de Indias, Hacienda de Indias, Comercio de Indias, y Gracia y Justicia de Indias. 
"... Si quedamos sin poner en uso el asiento de negros cesando la guerra, difícilmente nos lo sacarán en un congreso y, el librarnos de él, es la mayor importancia de Indias..."10.

Y añade otras observaciones:

"... en cómo pongo lo de la libre navegación, que es con sus mismas palabras, que son las que clama el pueblo, y en viéndolas se aquietará. Los doctos del vascuence [Villarias] temen ésa sobre todo y yo temo más el asiento de negros y navío de permiso. Verdad es que la liberta[d] de uno y otro no la pido, que la pago y, en realidad, se acabó ya su tiempo..." ${ }^{\prime \prime 1}$.

El concepto de "libre navegación" utilizado por Carvajal no está referido a la concesión de un "comercio libre", sino, como los propios británicos defendían, a un "mare liberum" para los productos y navíos nacionales y un "m are clausum" para el resto de países extranjeros. En cuanto a la "libertad" del asiento y navío de permiso, se refiere al pago de una cantidad en metálico por la renuncia de estas concesiones, que incluso podría llegar, como veremos más adelante, a la formación de una compañía privilegiada hispano-inglesa en el mercado colonial español.

Es interesante la respuesta de Huéscar:

"...Soy poco sastre para decidir sobre materias de libre navegación y preferir las ventajas de ésta o del asiento de negros, pero en mi corto entender aventuramos poco en convenir en la libre navegación según la propones, respecto de que es importante evitarla y perderíamos mucho si el asiento de negros y el navío del permiso continuasen..." ${ }^{\prime 2}$.

En el Testamento Político Carvajal también dedica unas líneas a estos asuntos:

"...Otro embarazo es el Asiento de Negros, este nos destruye y da motivo a quejas y alteraciones..., porque para la nación en general no es lucroso el asiento si no es para varios individuos..."13.

Y más adelante escribe:

"... Importa infinito que no haya Asiento de Negros de nación extranjera, sea la que fuere..."14.

10. Véase el epistolario entre Carvajal y Huéscar, carta del 29 de mayo de 1747, en OZANAM, D., op.cit., 163. La obra de Ozanam presta más atención a las relaciones internacionales entre 1746-1749 que a los asuntos comerciales con América.

11. Véase el epistolario de Carvajal a Huéscar, carta del 18 de marzo de 1747, en OZANAM, D., op.cit., 163.

12. Véase Huéscar a Carvajal, carta del 5 de abril de 1747, en OZANAM, D. op.cit., 163.

13. Véase CARVAJAL Y LANCASTER, J., Testamento Político..., op.cit., 16.

14. Véase CARVAJAL Y LANCASTER, J., Testamento Político..., op.cit., 106. 


\section{Los proyectos de compañías privilegiadas de carvajal}

Las Reales Compañías de Fábrica y Comercio fueron una combinación entre las compañías de comercio tradicionales y las compañías fabriles del interior peninsular con privilegios comerciales en América. Estas compañías fueron, entre otras, la de Extremadura y Zaragoza (1746), Sevilla y Granada (1747) y Toledo (1748), bajo el control de la Junta de Comercio y Moneda.

Precisamente la "Representación" de 1752 fue un alegato contra el Real Decreto de 1752 elaborado por Ensenada, que extinguía los privilegios exclusivos de estas compañías. Carvajal, responsable de las Reales Compañías de Fábrica y Comercio desde 1746, no guardó silencio ante tal revés. El duro golpe a los privilegios de las compañías necesitaba una respuesta inmediata. En la "Representación" Carvajal atacó directamente la política de Ensenada, el poder de los extranjeros y la mediocridad de algunos escritores, que prueba la intervención de estas obras en la práctica política.

Pero el eje principal del ideario carvajaliano fueron los proyectos de compañías privilegiadas de comercio. La principal defensa de estas compañías está localizada en el "Testamento Político" de 1745, concretamente en el epígrafe Comercio con Indias. Allí Carvajal definió el concepto de compañía, defendió la Real Compañía Guipuzcoana de Caracas (1728) y La Habana (1740), estableció sus ventajas, criticó el exclusivismo portuario de la Carrera de Indias $y$, por último, proyectó 12 compañías provinciales en áreas comerciales españolas y americanas.

Carvajal definió así la compañía privilegiada:

“... Compañía es una colección de caudales de muchos indiviauos destinada a una negociación que sólo ellos participan en pérdidas y ganancias, regida portres o cuatro elegidos por todos con permiso del Soberano..."15.

Defendió las compañías en funcionamiento. Dedicó unas líneas a la Real Compañía de La Habana:

“...El Rey ha de mantener siempre el asiento de los tabacos a la compañía de La Habana, y a esta fomentarla y cuidar de su mayor opulencia, no sólo por los altos fines de los dominios de Indias, sino también porque los de este asiento sólo se pueden lograr por ella..."16.

Señaló algunas mejoras en su organización, siempre favorecedoras de una mayor participación portuaria, o aperturismo portuario, en los beneficios del comercio americano:

15. Véase CARVAJAL Y LANCASTER, J. Testamento Político..., op.cit., 123.

16. Ibid., 40 . 
“... convendrá mucho que la compañía venga a desembarcar sus tabacos a todos los puertos donde los reciba el administrador de tabacos, con eso a todas partes llegará de todas castas, y se gastará más y se ahorrará infinito en portes por tierra que se gasta llevándolo desde Sevilla..."${ }^{17}$.

Las ventajas de la fundación de compañías privilegiadas fueron múltiples:

"...Fórmense compañías para Indias y así se hará este comercio con caudal de españoles, y le habrá, se evitará el contrabando sin disensiones con extranjeros y florecerán estos y aquellos dominios..." ${ }^{\prime 1}$.

Pero estas ventajas no garantizaron su articulación y éxito frente a los intereses del monopolio gaditano, que funcionaba como una gran compañía privilegiada. La historiografía ha considerado a Adam Smith responsable de la comparación entre el exclusivismo portuario de la Carrera de Indias y las características de una compañía privilegiada ${ }^{19}$, pasando más desapercibidas las ideas de José de Carvajal:

“... El comercio de Cádiz no es otra cosa que una compañía informe o mala, y la prueba es clara... [en Cádiz] sólo gozan de la negociación de Indias los individuos matriculados, donde sólo el caudal de estos hace este comercio, y sólo ellos participan las pérdidas o ganancias... pues siendo esto así, ¿de dónde viene este aborrecimiento al nombre de compañía..."20.

También Campomanes comparaba de algún modo los privilegios exclusivos concedidos a las compañías privilegiadas comerciales con los que detentaba Cádiz ${ }^{21}$.

La idea básica del sistema plural de compañías fue el siguiente:

"... Tengo por de la mayor importancia que cada compañía se sitúe en diferente puerto del Océano y del Mediterráneo y aunque tengan que pasar el Estrecho, todo comercio riega y fertiliza infinito, pues gocen todos los dominios este riego, den por este medio salida a sus frutos, conozcan los de Indias, tómenles cariño, denles aprecio y tomen comprensión de este gran negocio..." ${ }^{22}$.

17. Ibid., 41-42.

18. Ibid., 124.

19. Véase MATILLA QUIZA, M.J. "Las Compañías Privilegiadas en la España del Antiguo Régimen", en La Economía española al final del Antiguo Régimen, Vol. IV. Banco de España, 1982, 292, en especial nota 8.

20. Véase CARVAJAL Y LANCASTER, Testamento Político, op.cit., 123.

21. Véase LLOMBART ROSA, V. Pedro Rodríguez Campomanes. Reflexiones sobre el comercio español a Indias. Edición y estudio preliminar. Clásicos del Pensamiento Económico Español. Madrid, 1988, XXXVIII.

22. Véase CARVAIAL Y LANCASTER, Testamento Político, op.cit., 126. 
Así, el principal objetivo era realizar el comercio activo con América facilitado por las condiciones políticas y económicas que disfrutaba España, rebajando los derechos fiscales y facilitando la navegación directa:

“... [hacer el comercio activo de la Monarquía Hispánica] en sus dominios de la Europa con los mismos suyos de la América... quiso dar a la Es paña en losde la América lo que le podía faltar en los de la Europa... ${ }^{\prime \prime 2}$.

El eje del proyecto estaba estructurado en la formación de doce compañ ías provinciales, incluidas la compañía de negros gaditana y la de Filipinas. Las zonas de acción privilegiadas fueron múltiples, -véase Cuadro I-, tanto en España como en América, buscando un equilibrio regional y una complementariedad económica entre las diferentes provincias. Estos proyectos de compañías tenían un escaso armazón institucional, ya sea administrativo o financiero, tal vez copiados de los modelos de la Real Compañía Guipuzcoana de Caracas (1728) y La Habana (1740).

Cuadro I. Los proyectos de compañías privilegiadas provinciales de Carvaja| ${ }^{25}$

\begin{tabular}{|l|l|l|}
\hline COMPAÑIA & REAS ESPAÑOLAS & AREAS AMERICANAS \\
\hline Castilla La Nueva & $\begin{array}{l}\text { La Coruña, u otro pueblo de } \\
\text { Galicia, salvo,El Ferrol (1). } \\
\text { Comprende Extremadura y La } \\
\text { Mancha }\end{array}$ & $\begin{array}{l}\text { Campenche, Gutemala, Honduras } \\
\text { y provincias superiores hasta el } \\
\text { Mar del Sur (Audencia deGuatemala) }\end{array}$ \\
\hline de Castilla La Vieja & $\begin{array}{l}\text { Santander,. Comprende Campos, } \\
\text { Astorga, Burgos y su Montaña y } \\
\text { La Rioja }\end{array}$ & $\begin{array}{l}\text { Nicaragua, Costa Rica, Veragua, } \\
\text { Darien, Porobelo y al sur hasta } \\
\text { Panamá y Chacles, incluida } \\
\text { Cartagena }\end{array}$ \\
\hline de Andalucía & $\begin{array}{l}\text { Sevilla (Puerto de los Pozos de } \\
\text { Chipiona). Comprende el reino } \\
\text { de Sevilla y los otros de } \\
\text { Andalucía }\end{array}$ & $\begin{array}{l}\text { Cartagena, Santa Fe, Chocó, } \\
\text { Popayán,Antioquía, Santa Marta } \\
\text { yodo el Vizreinato de Santa Fe } \\
\text { salvo las zonas anteriores y } \\
\text { Quinto }\end{array}$ \\
\hline
\end{tabular}

23. En otras palabras: "en llevando de acá [España], lo que les falta allá [América], traemos de allá lo que necesitamos acá". Véase CARVAJAL Y LANCASTER, Testamento Político, op.cit., 56.

24. Como ya dijimos esta obra de Carvajal ha sido publicada por MOZAS MESAS, $M$. Don José de Carvajal..., op.cit., 51 y sigs.

25. Fuentes: CARVAJAL Y LANCASTER. J. Testamento Político, op.cit., 128-142; y también ARTOLA, M. "América en el Pensamiento español del siglo XVIII", en Revista de Indias, $n^{\circ}$ 115-118. Madrid, 1969, 75-77. Nosotros hemos seguido el orden original de los proyectos de Carvajal.

(1) El Ferrol estaba destinado como puerto de la marina de guerra junto a Cartagena y Gibraltar. (2) "... quitando a [la Real Compañía de] La Habana proveer estas zonas..."; y teniendo como privilegios añadidos la libre entrada de armas en los puertos del Mar del Norte, las sacas de arboladuras de navíos, ventajas como compañía repobladora, etc. (3) Ventajas de población y a "... las compañías del Mar del Norte [estará] excluido el [comercio del] tabaco para preservar el monopolio de la [Real] Compañía de La Habana...". (4) Poblar el puerto de 
En la obra de Carvajal titulada "Mis Pensamientos", redactada en 1753 poco antes de su muerte, reflexionó y proyectó otras compañías privilegiadas ${ }^{24}$. Es difícil asegurar si hubo o no una evolución de las ideas sobre las compañías privilegiadas entre 1745-1753, aunque algún historiador ha señalado que "no existen más que pequeñas diferencias, debidas al tiempo y a la experiencia del poder". Es arriesgado establecer esta hipótesis ya que el escrito "Mis Pensamientos" fue una obra incompleta que afectó a los proyectos de compañías privilegiadas.

En "Mis Pensamientos" proyectó una compañía privilegiada de comercio con América, con participación inglesa y privilegio exclusivo durante 10 ó 15 años. La financiación correspondería en un $10 \%$ a cargo de los ingleses, $y$ el $90 \%$ restante a españoles. Estas ideas chocaban de plano con la crítica a la presencia extranjera en el comercio hispanoamericano.

Sin embargo, Carvajal advirtió estos inconvenientes y denunció el frágil, o casi utópico, monopolio español en América, sobre todo a partir de las concesiones del navío de permiso, el asiento de negros y la entrada de capital extranjero por la vía gaditana. Parecida idea fue apuntada por José Patiño cuando retrasó hasta 1744 las posibilidades de lograr con éxito una reforma general en el comercio con las Indias, precisamente al finalizar la concesión del navío de permiso a los ingleses ${ }^{26}$.

Los beneficios de este proyecto de compañías serían: aumentar el capital del comercio con Indias; administrar capital extranjero "por nuestras manos", aplicándolo donde se elija, sin fraudes, con ventajas en la administración y fomento de las manufacturas; los ingleses quedarían agradecidos y deudores; se evitaría el comercio ilícito de los ingleses; beneficio en las presas; ayuda de Inglaterra en la defensa de las Indias; y, por último, en caso de guerra nos quedaríamos con sus réditos y caudales invertidos. Incluso amplió el período de disfrute de estos privilegios:

" [porque]...en muchísimos años no puede la España llegar a tener fondo bastante para el Comercio de Indias, y que aún cuando llegara a esto, siempre necesitaría de algún apoyo para defender las Indias..." ${ }^{27}$.

Las mayores dificultades para el buen funcionamiento del proyecto serían el secreto frente a otras potencias y, concretamente, la oposición del Parlamento

\footnotetext{
San Julián en el Estrecho de Magallanes. (5) Atravesar la mercancía por ríos hasta Chile, entrando Navarra con la condición de Aduanas. (6) Esta compañía no es de provincia sino por acciones de particulares. (7) "... se han de encargar los guipuzcoanos ya que su compañía ha de tener precisa decadencia con la formación de las expresadas en Guatemala, Río de la Magdalena, Maracaibo y Guayaquil, todas producen cacao...". (8) Unica zona privilegiada fuera del continente americano y área caribeña.

26. Véase WALKER, G.L. Política española y comercio colonial, 1700-1779. Ariel. Barcelona, 1982, 212.

27. Véase estas ideas de Carvajal en MOZAS MESAS, M., op.cit., 72.
} 
inglés ${ }^{28}$. En definitiva, Carvajal insistió en la necesidad de una pluralidad de compañías privilegiadas como medio para fomentar el comercio americano:

“... La práctica será que en varias compañías, de que hablaré cuando apunte mis pensamientos sobre Indias y en lo que quede a comercio libre, aunque sea de un registro, declare el Rey que quiere interesarse en la quinta aparte y ponerla de capital..." ${ }^{\prime 29}$.

\section{Las fuentes de los proyectos de compañías comerciales de José de carvajal}

Es complejo localizar los modelos originales de los proyectos de compañías que pudieron influir en Carvajal, sobre todo por los escasos estudios sobre las ideas político-económicas y las compañías privilegiadas ${ }^{30}$.

En este artículo sólo pretendo analizar algunas ideas de Carvajal en torno a su época y no traspasar la barrera del siglo XVIII aunque, por ejemplo, bien pudiéramos iniciar nuestro estudio con la Junta de Comercio (1624) presidida por el Conde-Duque de Olivares bajo el reinado de Felipe IV (1621-1665) y toda la tradición arbitrista del siglo XVII.

En el siglo XVIII hubo una fase de mayor dinamismo y ambición en la formulación teórica y práctica de estos proyectos, aunque no fueron una novedad, favorecidos principalmente por la Junta de Comercio y Moneda (1746-1754). Entre los miembros de la Junta destacan, aparte del presidente José de Carvajal, los ministros José Ventura Güell y Trelles, Antonio Alvarez Abreu (Marqués de Regalía), Casimiro Uztáriz y Azuara (Marqués de Uztáriz), Juan Fermín de Barbaria, Pedro de Hontalba y Arce, Juan Ignacio de la Encina; los fiscales Juan Ignacio de la Encina, Ignacio de Ortega y Cotes, Francisco de Cepeda; y los secretarios Francisco Fernández de Samielos y Miguel de Oarrichena y Borda ${ }^{31}$. En parte esto explica el contexto de creación de los proyectos de Carvajal.

28. Debemos recordar que las compañías inglesas, a diferencia de las holandesas y portuguesas, no fueron de iniciativa particular o estatal sino mixtas, dada la doble composición política entre Monarquía y Parlamento. De hecho, la constitución de las compañías inglesas varió según el predominio de poder entre la Corona y el Parlamento. Algún historiador ha señalado que el Parlamento inglés se comportaba como un verdadero grupo de interés privado, sobre todo a partir del último tercio del siglo XVIII. Véanse las obras de THOMSON,J.E. Mercenaries, Pirates and Sovereigns. Staff Building and Extraterritorial Violence in Early Modern Europe. Priceton, 1994, 33; y ROOT, H.L. The Foundation of Privilege. Political Foundations of Markets in Old Regime France and England, University of California Press, 1993, 53.

29. Véase MOZAS MESAS, op.cit., 73.

30. La carencia de una monografía sobre el pensamiento económico y las compañías privilegiadas también ocurre en la historiografía europea, tal vez porque casi la mayoría de los pensadores económicos se ocuparon de estas compañías, o bien porque se presupone las opiniones de estos escritores.

31. Véase FRANCISCO OLMOS, J.M., op.cit., 390 y sigs. 
Por ejemplo, Carvajal citó en el Testamento Político a escritores español es interesados por estas compañías, como Gerónimo de Uztáriz y Miguel de Zava$\mathrm{la}^{32}$, aunque ninguno desarrolló un proyecto tan ambicioso como Carvajal. Uztáriz fue crítico con los privilegios concedidos a estas compañías y contrario a su formación en América; Zabala proyectó dos compañías, una para Nueva España y otra para Tierra Firme, pero dejó asentado el cimiento teórico del posteri or proyecto de Carvajal:

"...El modo de establecer este comercio según nos enseñan todas las naciones que fundan en su consistencia y aumento su poder, es el de formar compañías para aquellos negociados de la mayor importancia, destinando a cada una aquel que merece la mayor atención conforme al paraje en que se sitúa, ya sean con el nombre de las provincias donde se establezcan..." ${ }^{\prime 33}$.

En el "Testamento Político" no faltan las referencias de Richelieu y Colbert, ambosdefensores y promotores de una política favorecedora de compañías privi legiadas en Francia, buscando un reparto equitativo del comercio entre la metrópoli y sus colonias. Desde 1626 Richelieu intentó rescatar los proyectos de compañ ías privilegiadas que habían fracasado por no haber reunido el suficiente capital:

“... faire de grandes compagnies, obliger les marchands d'y entrer [...] [car]faute de ces compagnies et pour ce que chanque petir marchand trafique à part et de son bien, et partant pour la plupart en des petits vaisseaux et assez mal équipés, ils sont la proie des corsaires et des princes nos alliés, parce qu'ils n'ont pas les reins assez forts comme aurait une grande compagnie..." ${ }^{\prime 34}$.

Desde 1626-1627 Richelieu presentó un programa económico estableciendo numerosas compañías privilegiadas de comercio, con rasgos más políticos que económicos, como las compañías españolas del siglo XVIII. Entre otras destacaron la Compagnie du Morbihan (1626), Compagnie de la Terre Ferme de L'Amerique y Cent Associes de la Nouvelle France (1628).

32. Carvajal cita a Zabala cuando trata las rentas reales y dice que: "... el remedio a tanto mal es su sistema. Tengo su obra por dictada de Dios, para que algún día respire esta Monarquía...". Véase CARVAJAL Y LANCASTER, Testamento Político..., 34. Las citas de Uztáriz se refieren a la desidia de la nación española y al trabajo consular.

33. Véase ZABALA Y AUÑÓN, MIGUEL DE. Miscelánea económico-política o discursos varios sobre el modo de aliviar los vasallos con aumento del Real Erario [1732]. Imprenta de Antonio Espinosa. Madrid, 1787, 190.

34. Véase HAUDRERE, P.H. "Jalons pour une histoire des Compagnies des Indes", en Compagnies et comptoirs L'Indes des Francais XVIIe-XXe siécle. Biblioteque d'Histoire d'Outre-Mer. Nouvelle Serie. Etudes 12. París, 1991, 10. El texto de Richelieu aparece citado en la obra de FRESNE DE FRANCHEVILLE, J. Histoire de la Compagnies des Indes, París, 1746, 164-165. 
Este programa de Richelieu continuó con la política comercial de Colbert como Intendente de Finanzas (1661-1665) y Contador General (1665-1683). Los principales puntos de su política fueron el fomento de las exportaciones, la prohibición de la exportación de moneda y reducción de la importación, con el objetivo de crear un reino autosuficiente bajo el control del Estado. Dentro de esta política comercial aparecieron la Compagnie des Indes Orientales, la Compagnie des Indies Occidentales (1664) y la Compagnie Du Nord (1669)35.

Otros datos indirectos, posiblemente relacionados con el origen de los proyectos de compañías plurales o al menos de algunas de sus características y elementos, los facilita el Intendente Rodrigo Caballero, quien entre 1720-1723 defendió la necesidad de crear tantas compañías como provincias, adelantándose a la reflexión teórica de Zabala y al proyecto de José de Carvajal.

Un objetivo del programa político de José Patiño fue la conexión espacial y el equilibrio territorial de la Monarquía Hispánica entre el Mediterráneo y el Atlántico por medio de una compañía. Su proyecto era convertir Cádiz en una de las sedes de la Compañía de Ostende (1732-1735), uniendo los puertos italianos de Livorno y Trieste con los del Norte de Europa en el Mar Báltico. El fracaso de la compañía por las presiones extranjeras acabó con este proyecto.

El proyecto de Juan Amor de Soria (1740), en esta misma línea racional y equilibradora del territorio, defiende un sistema plural de compañías privilegiadas repartidas entre las tres vertientes marítimas españolas ${ }^{36}$. Por último, Marcelo Dantini (1741), un italiano buen conocedor de la Carrera de Indias y de los abusos del comercio español y extranjero en América, proyectó $13 \mathrm{com}$ pañías privilegiadas repartidas entre distintos puertos españoles con zonas de acción privilegiada en América ${ }^{37}$. Este proyecto es más completo que el sistema de José de Carvajal en la organización teórico-práctica y en la formulación de objetivos, incluso faltándole buena parte de los proyectos de compañías.

\section{La influencia de los proyectos de Carvajal}

En vida de José de Carvajal sus obras permanecieron manuscritas. No fue hasta 1789 cuando fue publicada por primera vez la "Representación", y debemos esperar hasta 1818 para encontrar editado el "Testamento Político". Precisamente en el "Testamento Político" (1745), obra que recoge los principales

35. Véanse estas compañías privilegiadas francesas en BOULE, P.H. "French mercantilism, commercial companies and colonial profitability", en BLUSSE-GAASTRA (Edit): Companies and Trade (Essays overseas trading companies during the Ancien Regime). Leiden University Press. Leiden, 1981, 107.

36. Véase DELGADO BARRADO, J. M. "Puertos privilegiados y ordenación territorial: el proyecto de Juan de Amor de Soria (1741)", en Monarquía, Imperio y pueblos en la España Moderna. Actas del IV Congreso de la Asociación Española de Historia Moderna. Alicante, $1997,189-200$. 
proyectos de compañías, queda definida la intención del autor en cuanto a la publicación de su obra:

“... Que no escribo para que se imprima, la obra lo está diciendo, porque ahora no se viera sin riesgo mío según hablo y en todo tiempo fuera muy perjudicial al reino que se publicara, y así no que pensaba hacerlo, ni que lo hacia he pronunciado..." ${ }^{\prime 38}$.

Esta transmisión manuscrita nos habla de un mayor interés por la acción de gobierno que por la difusión del manuscrito y sus ideas, al igual que sucedió con otros escritores político-económicos del siglo XVIII como Campillo y Ward ${ }^{39}$.

Para hallar la posterior influencia de sus ideas debemos analizar otras obras político-económicas y planes de reforma comercial. Estos datos pueden dividirse en dos grandes bloques, ya sean de ámbito nacional o internacional.

El ámbito nacional está dividido en dos: los escritores político-económicos y la política comercial de la Monarquía Hispánica. En los escritos político-económicos destacó la obra del marqués de los Llanos (1755) y su proyecto plural de compañías, -coincidiendo con la creación de la Real Compañía de Barcelona (1755-1756)-, enfocadas a una mayor participación de las provincias de España en el comercio americano:

"... el repartimiento del comercio de la América entre las provincias de España parece el más suave y el más ventajoso a enriquecer este reino y cuidar y tener bien provistos aquellos... Cada provincia o puerto de España cuidará de la parte o porción que le cupiere como que en ello interesa su felicidad, crecerá entre todas la emulación de aventajarse. $Y$ sólo tendrá el ministerio que hacer en mantener el equilibrio entre ellas para que hallará más facilidad en las mismas luces que le suministraran unas y otras..." ${ }^{\prime 40}$.

Jaime Huguet y Génover en 1784 rescató parecidas ideas en un proyecto de múltiples compañías privilegiadas:

37. Véase DELGADO BARRADO, J.M. Fomento portuario y puertos privilegiados: Los "Diálogos Familiares" de Marcelo Dantini (1741-1748) CSIC, Madrid, 1998.

38. Véase CARVAJAL Y LANCASTER, Testamento Político...,op.cit., 2.

39. Véase sobre la transmisión de un texto manuscrito y los ejemplos de Campillo y Ward el artículo de GUIMERA RAVINA, A. y DELGADO BARRADO, J.M. "El proceso de transmisión de un texto manuscrito del siglo XVIII: Los "Diálogos Familiares" de Marcelo Dantini (1741-1748)", en Homenaje a A. Aguilar Piñal, Madrid, 1996, 493-507.

40. Véase LLANOS, MARQUÉS DE LOS, Papel del... haciendo presentes los medios con que puede conseguirse la felicidad de la Monarquía con el aumento de su población, labor, cría de ganados y el de su comercio y navegación... Biblioteca de Palacio, Madrid, 1755,101-115. 
"... seria muy del caso que Vuestra Majestad aumentase y fundase tan tas compañías como puertos hay en España proporcionados para el comercio, a fin de que todo el reino gozase de este benéfico influjo y, si se juzgase útil, en algunos puertos duplicar las compañías, librando Vuestra Majestad para cada una cien mil pesos..."41.

La evolución de la realidad comercial española facilitó un vacío teórico entre Llanos (1755) y Génover (1784), gracias a una coyuntura política y comercial poco favorecedora a los proyectos de compañías.

En la política comercial española observamos algunas huellas de las ideas de José de Carvajal. La Real Compañía de Barcelona (1755), fundada poco después de su muerte, fue una de las compañías proyectadas por Carvajal, aunque no concuerden exactamente todas las zonas de privilegio comercial con los privilegios conseguidos por esta compañía ${ }^{42}$.

El proyecto de Carvajal defendió el aperturismo portuario con América. Este también fue el principal objetivo de la Junta de Expertos de 1764, origen de la futura habilitación portuaria de 1765. En este sentido "aperturista" las zonas de acción privilegiada de Carvajal fueron más ambiciosas que las proyectadas por los miembros de la Junta de Expertos y el Real Decreto. Sin embargo, desde el punto de vista liberalizador, las compañías no superaron, ni compitieron, con la reglamentación de la habilitación portuaria de 1765. En el fondo lo verdaderamente importante es saber qué proyecto estuvo más acorde con la realidad comercial, sobre todo con la tradición, y las posibilidades reales de los nuevos puertos habilitados, para no predisponerlos al más rotundo de los fracasos.

Por último, la teoría de Carvajal sobre el traspaso de responsabilidades de la Real Compañía Guipuzcoana de Caracas al mercado filipino, fue aprovechada por Cabarrús en 1785 para crear la Real Compañía de Filipinas, partiendo de la herencia institucional de la Guipuzcoana. Hasta la fecha la historiografía señalaba a Bernardo de Iriarte (1781) como autor de estas ideas:

“... La novedad de su idea consiste en que él [Bernardo de Iriarte] fue quien pensó primero en la Compañía Guipuzcoana de Caracas como base de la futura empresa, bajo distinto método y con más acertada dirección que hasta aquí ha tenido..." ${ }^{143}$.

41. Véanse las ideas de Huguet y Génover, concretamente el punto 24 de su proyecto, citado por GARCÍA RUIPÉREZ, M. "El pensamiento económico ilustrado y las compañías de comercio", en Revista de Historia Económica, Centro de Estudiso Constitucionales. Año IV, n 3, 1986, 540.

42. Véase el proyecto de José de Carvajal como uno de los posibles orígenes de la compañía barcelonesa en OLIVA MELGAR, J.M. Cataluña y el Comercio Privilegiado con América. La Real Compañía de Comercio de Barcelona a Indias. Temes Historia. Barcelona, 1987.

43. Véase DíAZ-TRECHUELO SPINOLA, M.L. La Real Compañía de Filipinas. Escuela de estudios Hispano-Americanos de Sevilla. CSIC. Sevilla, 1965, 26. Bernardo de Iriarte fue un ilustrado canario buen conocedor de los regímenes de excepción comercial. 
En el ámbito internacional es más complicado establecer hipótesis sobre I a transmisión de los proyectos de compañías de Carvajal. Los estados receptores de estas ideas político-económicas estaban reducidos a unos pocos, precisamente aquellos que no poseían una larga tradición práctica en este tipo de empresas y que necesitaban modelos mercantiles de expansión comercial. Durante el siglo XVIII las políticas mercantilistas de Dinamarca, Portugal, algunos estados italianos y Prusia, entre otros, favorecieron la emergencia de compañías privilegiadas. Parece lógico pensar que la proximidad geográfica y política del reino de Portugal y las Dos Sicilias favoreciesen un mejor y más fácil intercambio de estas ideas. Por ahora, y por motivos de espacio, me centraré en el caso del reino de las Dos Sicilias ${ }^{44}$, donde la historiografía ha señalado la influencia de escritores españoles, como Gerónimo de Uztáriz y Bernardo de Ulloa, en autores napolitanos, como Antonio Genoves ${ }^{45}$.

Durante estos años la política comercial napolitana estuvo dominada por los problemas internacionales - dependencia frente a otros centros mercantiles- y nacionales -dadas las características específicas de su comercio de importación de manufacturas y exportación de materias primas-.

La defensa de una política proteccionista hubiera disgustado a las naciones amigas; por contra una política expansionista con la ampliación del comercio exterior, hubiera dañado los intereses particulares de algunos estados europeos como Inglaterra, Holanda y Francia. Parecería lógico centrarse entonces en el comercio interior. Sin embargo el comercio interior napolitano estaba lleno de obstáculos: falta de incentivos, usura en los préstamos, lentitud judicial en los aspectos comerciales, deficientes sistemas de transportes, etc. Así, conseguir una política comercial autónoma pasaba por una política exterior y comercial determinada por los tratados de paz, comercio y navegación con otros estados europeos.

De este modo el interés de Nápoles por el comercio americano fue tomando consistencia a lo largo del siglo XVIII ya que, teóricamente, los aspectos de proximidad política entre Nápoles y España, facilitarían un buen entendimiento en materia comercial, principalmente en el monopolio colonial español.

La historiografía italiana marca el inicio de este interés en la guerra hispanoinglesa de 1739, aunque existieron proyectos precedentes de comercio con América gracias a las compañías privilegiadas, como la De La Roche-Jauna (1737-1742); las ideas de fomento marítimo de Grimaldi (1734), Vaucouller (1736) y otros $^{46} ;$ y, posteriormente, la propia realidad comercial, con expedi-

44. La historia comparada entre la política comercial hispano-lusa, bajo el gobierno de Carvajal y Pombal, merece un trato preferencial, objeto de un futuro trabajo.

45. Véase VENTURI, F. "Economistas y reformadores españoles e italianos del siglo XVIII", en Textos olvidados. Presentación y selección de Fabián Estapé y Rodríguez. Instituto de Estudios Fiscales. Madrid, 1988, 203-240.

46. Sobre estas ideas véase DELGADO BARRADO, J.M. "Puerto y privilegio en España y los estados italianos durante el siglo XVIII", en GUIMERA RAVINA y ROMERO (Edit): Puertos y sistemas portuarios (siglos XVI-XX). Madrid, 1996, 260-262. 
ciones de comerciantes napolitanos y la formación de compañías particulares de comercio en las Indias Occidentales ${ }^{47}$.

Giovan Battista María Jannucci (1767-1768), en la obra titulada "Economia delCommercio del Regno di Napoli", defendió la formación de compañías privilegiadas. Algunos aspectos de su trayectoria política coincidieron con José de Carvajal. Ambos fueron personajes con responsabilidades políticas y estuvieron interesados en el fomento marítimo y portuario; en las compañías privilegiadas plurales con el objetivo de equilibrar las riquezas de las provincias, el desarrollo de las exportaciones y el máximo aprovechamiento del mercado coloni al; y, por último, en los males del comercio exterior y sus posibles soluciones.

El sistema de compañías proyectado por Jannucci ha pasado casi desapercibido para la historiografía italiana. Por ejemplo, Elvira Contino estudió el proyecto general de compañías, a imitación de las holandesas, integrada en una adecuada organización interna del reino y unida a una eficiente red consular para coordinar el comercio marítimo hasta en los puertos exteriores más le janos. Pero no describió la organización provincial del sistema de compañías privilegiadas.

Estas compañías debían estar sostenidas con la intervención y apoyo de los órganos de gobierno, porque necesitaban elevados capitales para su constitución, la concesión de privilegios particulares y la exempciones para su buen mantenimiento. El problema de la financiación podrían resolverse estableciendo una sociedad por acciones que había funcionado en otras ocasiones. Las garantías del Estado y el aprovechamiento del sistema portuario del reino fomentarían el limitado desarrollo manufacturero del reino ${ }^{48}$. Así proyectaba unir las rutas o flujos del tráfico marítimo y comercial con la creación de una compañía en todas las ciudades importantes del reino, para aumentar la circulación monetaria y evitar la emigración de pequeños artesanos ${ }^{49}$. Este proyecto parece tener relación con las ideas de Rodrigo Caballero, Zabala y Carvajal, gracias, tal vez, a las referencias facilitadas por la obra de Antonio Genovesi, de gran influencia en los escritores napolitanos de la época ${ }^{50}$, y la práctica reformista española en el mundo comercial napolitano.

47. Véase en la obra de CONTINO, E. Mire di espansione commerciale del Regno di Napoli nel secolo XVIII. I progetti di Compagnie con le Indie Orientali. Istituto Universitario Navale, Nápoles, 1990, 37-38, algunas expediciones comerciales napolitanas a las Indias Occidentales (desde 1759) y la compañía de comercio particular de Lucio La Marra (al menos desde 1757).

48. Véase CONTINO, E. Mire di espansione..., op.cit., 35.

49. Véase el excelente estudio de ASSANTE, F. Giovan Battista María Jannucci. Economia del commercio del Regno di Napoli (1767-1768). Nápoles, 1981.

50. Véase el artículo de VENTURI, F. Economistas...,op.cit., 203-240, sobre la influencia de los escritores político-económicos españoles en los pensadores napolitanos. 


\section{Conclusiones}

La obsesión de José de Carvajal y Lancáster por las compañías privilegia das de comercio es una política generalizada en toda Europa. Es conveniente señalar los diferentes resultados entre las compañías privilegiadas americanas y asiáticas. Las condiciones y características de estas áreas favorecieron más la emergencia de las compañías asiáticas que las americanas. Las compañías americanas encontraron un espacio comercial poco estructurado, falto de los mecanismo básicos para un intercambio a gran escala y muy competitivo, que dificultaba el intercambio comercial sin el uso de la fuerza.

En el caso español estos proyectos de compañías fueron compatibles con el sistema tradicional de la Carrera de Indias, ya que sus zonas privilegiadas eran provincias marginadas fuera del exclusivismo portuario gaditano. Precisamente Carvajal advertía que no se debían establecer compañías en Perú y México, sobre todo por no chocar con los intereses de los comerciantes de la Carrera de Indias y las naciones extranjeras. Estas compañías no fueron proyectadas como "piedra filosofal" de los males del comercio colonial, sino como un medio provisional, una etapa más dentro de la política comercial de la Monarquía Hispánica, que convivió con flotas y galeones, registros sueltos, navíos de correos, permisos de toneladas y habilitaciones portuarias. Carvajal defendió las compañías privilegiadas, muchas veces no calculando sus limitaciones financieras y la voluntad de los comerciantes, y fue representante del punto culminante en la defensa y protección de estas compañías, frente a las críticas de otros escritores y políticos, como el Duque de Sotomayor y el Marqués de la Ensenada.

Como hemos visto, el sistema de compañías provinciales no fue un proyecto original de Carvajal, salvo la ordenación de las compañías con sus zonas de acción privilegiada. Anteriores escritores político-económicos, como Zabala, Amor de Soria y Marcelo Dantini, trataron en sus proyectos el sistema plural de compañías privilegiadas; incluso mejor elaborados, desarrollados y proyectados que José de Carvajal. Sin embargo, José de Carvajal fue un hombre de Estado, ministro de la Monarquía y, por lo tanto, su ideario teórico tuvo más posibilidades de éxito. Carvajal seleccionó las zonas de privilegio con un conocimiento muy agudo de la tradición comercial y las necesidades de cada provincia, y algunas de ellas fueron una realidad, por ejemplo la Real Compañía de Barcelona (1755) y Filipinas (1785); y, por último, fue un destacado representante de las críticas hacia el exclusivismo portuario gaditano, pero sin desligitimizarlo.

Carvajal utilizó fuentes españolas como los escritos de Gerónimo de Uztáriz y Miguel de Zabala y Auñón. Hipotéticamente aprovechó las ideas de otros autores menos conocidos como Juan Amor de Soria y Marcelo Dantini, tal vez gracias a la Junta de Comercio y Moneda, por donde pasaban numerosos escritos político-económicos. También fue receptor de las ideas comerciales francesas encarnadas en la política de Richelieu y Colbert. 
Las ideas de Carvajal sobre el comercio colonial, especialmente las relacionadas con las compañías, marcaron un hito en la política y pensamiento comercial español. Fueron cenit de un proceso iniciado en siglos pasados y que continuó, con mayor o menor éxito, a lo largo del siglo XVIII, cuando el tiempo de las compañías había pasado en Europa. Fue un nexo de unión entre el pasado -representado por las compañías privilegiadas- y el futuro -con las habilitaciones portuarias de 1765 y 1778-. En el fondo su proyecto de múltiples compañías fue un proyecto marítimo y comercial en defensa del aperturismo portuario favoreciendo una mayor participación de las provincias españolas en el comercio colonial, fuera del exclusivismo portuario gaditano, todo a través de un utópico equilibrio entre intereses particulares y felicidad pública, entre las presiones de los enemigos de las compañías, las naciones extranjeras y la realidad comercial de la Monarquía Hispánica. Sin embargo, la experiencia nacional y europea había demostrado con dureza que estas empresas no tenían éxito en todos los países, ni bajo cualquier circunstancia. 